\title{
О вербализации концепта «место кофепития» в русском и польском языках
}

\author{
ЭВА СТРАСЬ \\ Ewa STRAŚ, Uniwersytet Śląski, Instytut Filologii Wschodniosłowiańskiej, \\ ul. Grota-Roweckiego 5, PL-41-205 Sosnowiec \\ Institute of Eastern Slavic Philology, University of Silesia \\ E-mail: ewa.stras@us.edu.pl
}

(Received: 22 February 2018; accepted: 30 May 2018)

\begin{abstract}
The present paper is devoted to issues related to creating a universal concept of café in the mentality of Russian and Polish speakers. In this paper, it is descriptively presented as 'a coffee-drinking place'. The results of the analysis do not allow for clearly establishing the name of this concept in the consciousness of Russian-language speakers. By contrast, in the mentality of Polish speakers, the discussed concept is included in the notion of "kawiarnia" (i.e. 'café') and it is verbalised by the same word kawiarnia.
\end{abstract}

Keywords: Russian, Polish, concept, mentality, café, kawiarnia

Концепт, как единица изучения языка, вызвав активный интерес среди лингвистов, получил широкий спектр описаний и интерпретаций, иллюстрирующих весьма неоднозначный способ его понимания. Достаточно упомянуть фамилии таких исследователей, как Е. С. Кубрякова, В. И. Карасик, С. Г. Воркачев, В. В. Красных, З. Д. Попова, И. А. Стернин и др. Определение концепта в работах двух последних было использовано нами в качестве основы исследования. Названные авторы характеризуют концепт как «дискретное ментальное образование, являющееся базовой единицей мыслительного кода человека, обладающее относительно упорядоченной внутренней структурой, представляющее собой результат познавательной деятельности и несущее комплексную, энциклопедическую информацию об отражаемом предмете или явлении» (ПоПовА-СтЕРнин 2007: 24).

Процесс объективации концепта нуждается в изучении совокупности вербализирующих его единиц, группируемых в номинативном поле концепта, а в дальнейшем также и при исследовании его структуры. Объективизация же формируется разными понятийными признаками (дифференциальными или интегрирующими), выделяемыми на основании изучения словарных дефиниций, проверки контекстуального употребления и анкетирования (ПоПОВА-Стернин 2007: 47, 112, 113).

Следуя опыту многих исследователей и стараясь сохранить перечисленные аспекты исследования, в нашей работе мы предлагаем анализ, совмещающий лингвокогнитивный и лингвокультурный подходы, сосредоточив внимание на концепте, установление имени которого для русского языкового 
сознания встречается с определенными затруднениями. Вызвано это достаточно продолжительным процессом концептуализации, отображаемым составом языковых средств, вербализирующих разбираемый концепт. В связи с чем объектом исследования будет указанное в заглавии явление, представляемое как концепт, в то время как предметом - особенности его структурирования в языковой картине мира, а также способы объективации и выражения с помощью языковых единиц. Выбранная в таком повороте тема видится актуальной: неуклонно растет интерес к явлениям, связываемым с языковой картиной мира, вследствие этого появляется большое число работ, посвященных проблемам концептуализации реальной действительности.

Как бы ни отличались между собой толкования концепта, неизменно он остается единицей мышления, отражающей особенности культурных представлений народа, на которые накладываются история и традиция. Формирование представления о предмете, а в дальнейшем концепта, происходит в связи с появлением в реальной действительности какого-либо нового предмета или явления, получающего, в конечном итоге, свою реализацию в языке. Любая единица словаря, как известно, оказывается в составе определенной группы лексем, организуемых на соответствующем уровне языковой системы в виде лексико-семантического поля. Описание подобных полей было предпринято в свое время исследовательским коллективом под руководством Н. Ю. Шведовой, после чего представлено и опубликовано в виде «Русского семантического словаря». Лексические воплощения интересующего нас концепта нашли свое отражение в лексико-семантическом поле, названном «Столовые. Рестораны. Кафе», входящем в состав макрополя «Предприятия общественного питания» (ШвЕдовА 2000: 507-508). На этом фоне и будет предприниматься попытка изучения возникновения и затем развития в сознании говорящих на русском, а также польском языках людей концепта, который охарактеризован нами несколько отвлеченно как «место кофепития». Предлагаемое, хотя и искусственное, образование наиболее адекватно отображает рассматриваемое явление, понимаемое не совсем точно, в отношении обоих языков, и нуждающееся поэтому в пояснении.

Материалом исследования послужили лексические единицы и словосочетания, отобранные из лексикографических источников и подтверждаемые использованием в текстах национальных корпусов русского (НКРЯ) и польского (NKJP) языков, обнаруживающие семантическую связь с напитками кофе / kawa и местами их потребления. Следует добавить, что данные «Русского семантического словаря» (23 словарные единицы) были существенно ограничены, в противном случае их разработка потребовала бы значительного объема. Для лучшего понимания поисков соответствующего имени концепта в начале анализа будет представлен исторический фон, способствующий уточнению процесса его объективации, сначала в русском, а затем и в польском языках.

Заведение, определяемое как место, указанное в заглавии, появилось одновременно с напитком в странах Ближнего Востока. Это было помещение, 
предназначенное для встреч, прежде всего, мужчин, где помимо кофе можно было покурить водяную трубку и послушать истории повествователей, для которых данное заведение было местом работы. Сходная модель подобного учреждения вместе с его общественной функцией через некоторое время появилась также в Европе. Первые заведения такого типа были основаны в XVII веке в Венецианской республике (см. VANTAL 1998: 98), а вместе с ними в Западную Европу была заимствована и традиция соответствующего времяпрепровождения.

Следующим пунктом развития указанных заведений, где можно было посидеть и побеседовать за чашкой кофе, стала Великобритания, а затем Франция и Германия. В России подобные заведения появились при царе-реформаторе Петре I, хотя популярность приобрели только с времен правления Анны Иоанновны (ШАБАЛИнА 2014: 529). Своим существованием они также обязаны появлению кофе. Само слово, означающее растение, его зерна и приготовляемый из них напиток, было заимствовано русским языком из английского coffeе или голландского koffie (ФАСМЕР 2: 355).

На фоне изложенной краткой истории становления концепта «место кофепития» интерес представляют его названия, существующие в языке. Именно им мы отведем внимание, обращаясь, в первую очередь, к русскому языку.

Первоначально номинации, обозначающие новое общественное заведение, отображали воздействие Запада. Влияние английского (coffee house) и немецкого (Kafehaus, Kaffeehaus) языков способствовало тому, что на раннем этапе развития интересующего нас концепта, в конце XVIII в., употреблялось калькированное с указанных определение кофейный дом, однозначно указывающее на место потребления кофе, что подтверждается фиксацией в словаре 'заведение, где продают вареный кофе и закуски' (Даль 2: 151). Причем применялось оно, прежде всего, при описании действительности западных стран, например: «Отсюда в кофейный дом, куда купцы заходят с биржи и из города и находят закуску а 3 penny, уже готовую, и на тарелках означено, из чего каждая закуска составлена: говядина, баранина, ветчина; все вымерено и всему определенная цена» (А. И. Тургенев: Дневники, 1825-1826).

Вместе с тем упомянутое название можно встретить также в тексте, посвященном Москве: «...место, на котором по оной отдаче собственным их коштом библиотека построена, а под нею кофейный дом, в котором ныне содержитца им по отдаче из откупа чай и кофе и протчие заморские питья...» (Экстракт Сената по прошению В. Киприанова о продаже ему земли, 1728). В данном случае кофейный дом появляется как место, напоминающее в большей степени склад или лавку с импортными товарами. Продажа готовых напитков в виде кофе и чая была там второстепенной деятельностью.

Обсуждаемое обозначение перестает использоваться к концу XIX в. Воспоминания современников, которые по причине объема приводиться нами не будут, создают определенный противовес В. И. Далю, сообщающему применительно к этому заведению лишь о закусках. На их основании можно прийти к выводу, что кофейный дом - это место, где можно было позавтракать, 
пообедать, поужинать, т. е. поесть основательно. Тем самым, в смысловой структуре языкового выражения, вербализирующего разбираемый концепт, помимо интегрирующего 'место кофепития', выделяется также дифференциальный признак 'еда'. Дополнительное указание на напиток содержится в первой части составного названия.

Следующая лексема, определяющая место, где подается кофе - это кофейная. Ее появление объясняется распадом приведенного ранее наименования с утратой последнего компонента и самостоятельной функцией первого, атрибутивного. Субстантивированное прилагательное, казалось бы, столь типичное для русского языка, в составе таких единиц, как чайная, рюмочная, закусочная, блинная, пельменная, пирожковая, а также столовая, гостиная, ванная и др., однако, не закрепилось. Слово кофейная подтверждается в НКРЯ только двумя словоупотреблениями XIX в.: «...таскался по кофейным, читал журналы, по вечерам ходил в театр» (И. С. Тургенев: Гамлет Щигровского уезда, 1849).

Данное слово не вошло в лексический состав русского языка, уступив место кофейне. Это последнее нуждается в комментарии. Оно появилось, по всей вероятности, вместе с кофейной, однако, по нашим предположениям, в то время, когда устанавливалось название напитка. Один из его вариантов (кофей) и стал производящей основой того и другого слова для обозначения места. Согласно корпусным данным, обсуждаемый вариант, кофейня, появился в русском языке в первой половине XIX в., о чем свидетельствует хотя бы такой пример: «Их можно всегда было видеть в кофейнях полутурецкой Бесарабии...» (А. С. Пушкин: Кирджали, 1834).

Показательно то, что В. И. Даль ставит кофейню в один ряд с кофейным домом, давая им общее пояснение 'заведение, где продают вареный кофе и закуски’ (ДАль 2: 151). Однако, по-видимому, ближе к началу ХХ в. кофейня определялась как 'заведение, где посетители пьют кофе' (УшАков 1: 1490), поскольку именно в таком значении в тридцатые годы XX в. фиксирует его словарь под редакцией Д. Н. Ушакова.

Если бы не дальнейшая судьба кофеен в советское время, о чем еще пойдет речь, то именно кофейня могла бы стать определяющим именем обсуждаемого концепта. В то же самое время почитатели французской культуры и кулинарного дела с сороковых годов XIX в. стали использовать для обозначения места кофепития французское слово саfé, первоначально в оригинальном написании, затем в кириллическом варианте - кафе. Это было название, применяемое к заведению, отличающемуся от кофейных и кофейных домов, поскольку в начале своего существования «французское кафе» специализировалось на десертах. Согласно сведениям, собранным А. Н. Шустовым, с течением времени оно совпало по ассортименту блюд с другими подобными предприятиями, предлагая закуски и обеды (Шустов 1991: 132), однако данный процесс развития на материале текстов из корпуса восстановить невозможно. В современном лексикографическом представлении кафе 'небольшой ресторан, где подают кофе, чай, закуски и т. п.' (БТС 1998: 423). 
В этом случае при обсуждении понятийных составляющих концепта указываются два признака - дифференциальный 'еда' и интегральный '(кофе)питие'. Исходя из словарного толкования, можно заметить сближение семантики лексической единицы с концептом «ресторан».

Итак, к концу XIX века в лексической системе русского языка оказались две параллельные единицы (кофейня и кафе), близкие друг к другу, но также и отличающиеся отсутствием/наличием концептуального компонента 'еда'. Лексема кофейня, как активная, просуществовала в русском языке до двадцатых годов XX века, обозначая 'заведение, где посетители пьют кофе'. Вместе с тем в словаре под редакцией Д. Н. Ушакова она снабжается пометой «устаревшее», что отражало на уровне лексики новый послереволюционный порядок (УшАКов 1: 1490). Кофейни перестали существовать в результате их национализации и превращения, преимущественно, в столовые. Восстанавливаются как самостоятельные заведения они только в начале девяностых годов прошлого столетия, что и способствовало возвращению слова кофейня в активное употребление (ОШ 1997: 301, ЕФРЕмОВА 2000: 728).

В настоящее время данное слово получает свое толкование как 'маленький ресторан с продажей кофе' (ОШ 1997: 301), ‘небольшое кафе, где готовят и подают кофе' (БТС 1998: 464). Хотя подобное положение не противоречит возможности потребления кофе, вместе с тем это не способствует выделению имени обсуждаемого концепта как ведущего, поскольку в обоих случаях появляется дифференциальный признак 'еда', который способствует сближению лексической единицы с концептом «ресторан».

В последнее время установлению статуса кофеен способствует государственный стандарт (ГОСТ Р 50647-2010), упоминающий о напитках и десертах, на второе место передвигая закуски. И это, видимо, правильное решение, поскольку количество заведений, называемых кофейней, быстро растет, а в своей деятельности они сближаются с кафе, предлагая завтраки, бизнесланчи, обеды. Как представляется, наблюдаемое расширение семантики кафе основывается на смежности функций обоих заведений, а также в продолжающемся их сближении, ведущем к вероятному совпадению. Во многом объясняется это тем, что после перехода лексемы кофейня в пассив в 20-е годы $\mathrm{XX}$ века всю семантическую нагрузку того и другого приняло на себя кафе, которое с момента своего появления было, по-видимому, «местом кофепития» очень недолго, став «небольшим рестораном». Судьбу эту, как нам кажется, разделит вскорости и вновь появившаяся кофейня.

Концепт, передаваемый языковой единицей кафе, подвергся в ментальности носителей языка настолько значительной модификации, что, став едва ли не универсальным, нуждается в уточнении. Широкая по своему семантическому объему лексема кафе детализируется, пополняясь и расширяясь оттенками разных значений, реализуемыми в виде двухкомпонентных обозначений с написанием через дефис типа кафе-автомат, кафе-бар, кафе-гриль, кафе-клуб, кафе-кондитерская, кафе-молочная, кафе-мороженое, кафе-столовая и кафе-шашлычная (ШведовА 2000: 506). Вторая часть каждого из этих 
сложений указывает на самые разные характеристики, благодаря которым можно воспринимать перечисленные единицы как обладающие когнитивным классифицирующим признаком, позволяющим относить их к группе «заведения общественного питания». С другой стороны, все эти названия находятся на периферии обсуждаемого в настоящем исследовании концептуального поля, за исключением кафе-кондитерской, к которой мы еще вернемся по ходу анализа. Имеются также иные способы выражения как упомянутых, так и других характеризующих признаков, посредством, к примеру, сочетания с прилагательными, однако в настоящем исследовании мы их касаться не будем.

Среди лексем, обнаруживающих связь с кофе, следует упомянуть еще две - кафетерий и кафешантан. Первая из них определяется как 'небольшая закусочная, где подают кофе, легкие закуски’ (БТС 1998: 423). Это определение закусочной, заимствованное из испанского языка (cafeteria), возможно через посредство английского, где мотивировка словом café ‘кофе' видна без анализа. В семантике слова, подобно другим, выделяется дифференциальный признак 'еда', что позволяет отнести данное средство вербализации концепта «место кофепития» к периферийной зоне разбираемого концептуального поля.

Заимствованные из французского языка (café chantant) понятие и словарная единица кафешантан - 'кафе или ресторан с эстрадой, с исполнением музыкальных развлекательных номеров' (ШведовА 2000: 506), сочетались, как разумно было бы предположить, с дореволюционной или зарубежной действительностью. Дополнительно необходимо отметить, если учесть дифференциальный когнитивный признак 'еда', сближающий его (вербализатор концепта) с «рестораном», что данный выразитель рассматриваемого концепта занимает в структуре образуемого концептуального поля периферийное место. Обе рассматриваемые единицы не оказали существенного влияния на историю представлений о «месте кофепития» и становление его имени.

После обсуждения процесса формирования концепта в русском языке, перейдем к его рассмотрению в польском, где он представлен словарной единицей kawiarnia, мотивированной существительным kawa, заимствованным посредством турецкого kahve из арабского kahwa. Это последнее является апеллятивом, производимым от топонима Kaffa в южной Абиссинии, где росли дикие кофейные кусты (DŁugosz-KuRCZABOwA 2008: 299). Слово kawiarnia представляет собой дериват, образованный с помощью суффикса $-\operatorname{arni}(a)$ и входящий в словообразовательную группу названий места. Структура номинативной единицы однозначно указывает на связь с кофе и местом одновременно, следовательно, прямо становится именем концепта и когнитивного поля «место кофепития». Словарное толкование данного слова определяет его как 'lokal, w którym pije się kawę, herbatę i je ciastka' (WSJP), что можно свести к двум признакам - интегральному '(кофе)питие' и дифференциальному - 'десерт'. Так же, как и в случае русского концепта, обратимся сначала к истории. 
Традиция становления «места кофепития» в Польше складывалась, казалось бы, сходным образом, как и в России. Она также приходит с Запада, о чем свидетельствуют, давние определения: kafenhauz, kafenauz (SEJP 1970: 223), kafehauz (SJPD 3:463). Как пишет А. Брюкнер, это заимствования XVIII века из немецкого языка, указывающие на то, что данное заведение пришло из Германии, чему подтверждение можно увидеть хотя бы в таком описании: «Bardziej wszakże niż tańce wciągnęło go i porwało życie publiczne w kafenhauzach, z niemiecka urządzonych. Bilard, karty i tajemne uczęszczanie na pijatyki były przez całą zimę na porządku dziennym» (S. Żeromski: Popioły, 1904).

Вместе с тем, касаясь вопроса возникновения и развития «мест кофепития〉 в Польше, нельзя обойти молчанием историю венских кафе. Связующим звеном в этом случае можно считать фигуру Ф. Е. Кульчицкого, получившего в качестве трофея после Венской победы 1683 г. мешки с кофейными зернами и основавшего впоследствии первое заведение, предлагавшее кофе в столице Австрии. Тот же Ф. Е. Кульчицкий является автором рецепта для кофе с молоком и медом, то есть сладкого варианта горького напитка, ставшего впоследствии характерной особенностью венских кафе (VANTAL 1998: 105).

Одновременно с этим, начиная с двадцатых годов XVIII века, «места кофепития〉 появляются и в столице Польши. Происходит это в годы правления короля Августа II Сильного из саксонской династии Веттинов (НERBACZYŃSKI 1988: 34). Заведение было необходимо не столько самому королю, сколько его окружению: дворянам, служащим, гвардейцам, прислуге и т. п. В указанное время в Варшаве открылось несколько таких предприятий. Об одном из них - о кофейне госпожи Кольсоновой - так писали в свое время в газете «Kurjer Warszawski»: «...każdego czasu można u niej podwieczorkować, a za poprzedzającym uwiadomieniem wieczerzać i trzymać asamble...» (HERBACZYŃSKI 1988: 40).

Вместе с тем, то, что в варшавском заведении, именуемом kawiarnia, можно было также поесть, создает некоторый контраст традиции Кракова. В бывшей столице Польши кофе первоначально продавали в местах, называемых szynk kawowy (HомOLA-SKĄPSKA 1996: 52), что свидетельствует о не высокой изысканности напитка и места его потребления. Однако с середины XIX века появившееся новое заведение (kawiarnia) начинает конкурировать, а затем объединяться с «цукерней», предлагая, прежде всего, сладкую выпечку, торты и пирожные. Появление немалого числа заведений, называемых cukiernia, связано с развитием в Галиции свеклосахарной промышленности. Созданию конкурентных заведений способствовала мода и спрос на сладкое. Вероятно, не теряла своего значения также и традиция венских кафе. Следует добавить, что южные районы современной польской и частично украинской территорий находились с конца XVIII века под властью Австро-Венгерской монархии. Характер влияния краковских заведений на варшавские установить трудно, хотя можно предполагать, что такое влияние было, находя свое выражение в обновлении мебели, в совершенствовании стиля интерьера и в разнообразии предлагаемых десертов. 
Время, когда kafehauz заменяется словом kawiarnia, установить трудно, однако под влиянием немецкого языка, и не только на территории Польши, занятой Пруссией до 1918 года, первая из двух лексем удерживается довольно долго. Об этом свидетельствует, в частности, и ее фиксация в словаре шестидесятых годов XX века, хотя и с пометой «устаревшее» (SJPD 3: 464). Новая лексема (kawiarnia), заменившая заимствованную, продолжает свое существование без изменений до наших дней.

Еще одним заведением, доставлявшим жителям Речи Посполитой возможность культурного времяпрепровождения, была упоминавшаяся выше cukiernia, наиболее близкая к русской кондитерской. Ее связь с польской территорией и польским языком, а также отличие от заведений, именуемых кафе и kawiarnia, подтверждается данными НКРЯ: «Тем временем менее взыскательная молодежь, зная что ее на улице не оставят, осаждала пултусские цукерни и кавярни, без которых не обходится ни один польский городок» (Ф. Ф. Торнау: Воспоминания кавказского офицера, 1866-1880). Другой пример относится к Варшаве 1894 года: «А затем какая прелесть были встречавшиеся на каждом шагу кофейни-цукерни, где так весело гудел и свиристел хлесткий польский говор...» (А. Н. Бенуа: Жизнь художника, 1955).

Упоминаемые «цукерни и кавярни» существуют в Польше по настоящее время. В обеих, как правило, можно посидеть, отведать десерта и выпить кофе, хотя «цукерня» ориентирована в большей степени на продажу кондитерских изделий, а «кавярня» - кофе, что продолжает традицию XIX столетия. В русском языке лексема иукерня отсутствует, хотя разновидность таких заведений на территории России в то время существовала. Кондитерские, поскольку о них идет речь, пришли на смену «конфектным лавкам». В них можно было купить или заказать на дом что-нибудь сладкое, а также посидеть, выпить чаю, кофе или шоколаду, отведать сладкой выпечки, почитать газеты. С течением времени, однако, ассортимент кондитерских настолько расширился, что в них можно было также и пообедать. В результате, в связи с расширением предлагаемого ассортимента, происходит совмещение кондитерской с кафе и появляется кафе-кондитерская, упоминавшаяся ранее при обсуждении слова кафе.

В то же время к единицам, рассматривавшимся в употреблении русского языка, следовало бы добавить два заимствованных польским определения: редко употребляемое kafeteria 'kawiarnia', попавшее из французского (caféterie) (SJPD 3: 464) и вышедшее из употребления café chantant - помещение, в котором, прежде всего в XIX веке, публика пила различного рода напитки, курила сигареты, слушала песни, смотрела выступления артистов (KoPALIŃSKI 1999: 85). Следует при этом отметить, что первое из названных слов в современном польском языке, будучи редким, не употребляется. В то время как второе является историзмом и сближается с концептом «театр». Обе единицы, как лексические представители концепта «место кофепития», находятся на периферии концептуального поля, выражаемого средствами его языковой объективации. 
Подводя итоги, следует сказать, что «место кофепития» в русском языке в историческом отношении передавалось с помощью единиц кофейный дом, кофейная, кофейня, кафе, кафетерий, отражавших западную традицию места, где можно выпить кофе и при этом поесть. На начальном этапе сосуществования слова кафе и кофейня, по всей вероятности, семантически расходились, с течением времени сблизившись. То же самое происходит и в настоящее время, в чем можно убедиться, просматривая ресурсы Интернета: оба заведения предлагают очень близкие друг к другу составы блюд и напитков. Кафе сохраняет связь со своим первичным образцом, прежде всего, вследствие возможности потребления кофе, хотя при этом может быть и столовой, небольшим рестораном или закусочной на четыре столика.

Если обратиться к вопросу объективации средствами русского языка концепта «место кофепития», то можно заметить, что формировался он весьма динамично, особенно в случае таких единиц, как кофейня и кафе. Это обстоятельство сказывалось определенным образом на имени концепта, которое может выражаться обеими языковыми единицами. Если бы русской традицией было поддержано «французское кафе» со сладким ассортиментом блюд, то применяемое к нему наименование кафе могло бы сыграть роль единственного имени концепта. То же самое можно сказать о кофейне начала XX в. Но традиция, история и языковой узус настолько активно подействовали на сознание носителей русского языка, что в настоящее время совершить однозначный выбор вряд ли возможно. Все это дает основания указывать на этнокультурную специфику данного концепта в русском национальном сознании.

В свою очередь, исследуемый концепт в ментальности носителей польского языка подвергся осмыслению почти однозначным образом. В пояснении нуждается kafehauz, который удерживался в языковой системе достаточно долго, но, по-видимому, следовал изменяющейся во времени национальнокультурной специфике того же исходного немецкого концепта «Kaffeehaus». В сознании поляков традиция западного кафе несколько стерлась, подвергшись влиянию венских кафе, сочетаемых с «цукерней». Необходимо также сказать, что в основном эта традиция продолжается. К тому же польские «кавярни» не предлагают ничего, утоляющего голод, о чем свидетельствуют хотя бы такие примеры: «W Łazienkach jest tylko kawiarnia, a ciastkami trudno się najeść» (M. Sokołowski: Gady, 2007) или «Kiedy z koleżankami idzie do kawiarni, funduje sobie sok i ciastko» (Polityka, 4 grudnia 2008). Однако, если учитывать тенденции, наблюдаемые в современной польской действительности, то можно отметить явление, похожее на процесс, протекающий и в России, расширение ассортимента блюд. В указанных заведениях (kawiarni) можно также поесть, хотя, помимо сендвичей, врапов, запеканок, пиццы, обеденных блюд, в них можно заказать и то, что предлагается в другом традиционном заведении (cukierni) - кофе или другие напитки и десерт. Указанная особенность не относится к каждому заведению, однако это - тенденция, согласно с которой нарушаются границы определенного профиля заведений в пользу всеобщего, господствующего и унифицированного общественного питания. 
Сопоставляя лексические средства объективации концепта обоих языков, дающие представление об изучаемом концепте, можно прийти к выводу, что, с одной стороны, языковые системы их очень близки, в то время как с другой, они отличаются. Сразу бросается в глаза наличие в русском языке большого количества номинаций, уточняющих ассортимент, функцию или назначение этой разновидности заведения: кафе-молочная, кафе-клуб, кафегриль. И это только некоторые характеристики, отраженные в названиях. Образования польского языка представлены в данном отношении более скудно. Это свидетельствует о том, что границы концепта «kawiarnia», соответствующего «месту кофепития», настолько выразительно очерчены в сознании носителей польского языка, что редко нуждаются в уточнениях.

Подытоживая конкретизируемые в структуре концепта признаки, отображающие общественную жизнь носителей обоих языков, можно сказать, что они опираются на следующую особенность: в России в кафе или кофейне едят (завтракают, обедают, ужинают) и пьют кофе, а в Польше пьют кофе и едят сладкое (десерт). Обсуждаемая нами проблема получает свое подтверждение и в двуязычных польско-русских словарях, сопоставляющих словарную единицу kawiarnia с кофейней и кафе.

\section{Литература}

БТС 1998 = КузНЕцОВ С. А. (ред.) Большой толковый словарь русского языка. СанктПетербург, 1998.

Даль = ДАль В. И. Толковый словарь живого великорусского языка. Т. 1-4. Москва, $1978-1980$.

ЕФРЕМОВА 2000 = ЕФРемОВА Т. Ф. Новый словарь русского языка. Толково-словообразовательный. Москва, 2000.

НКРЯ = Наииональный корпус русского языка. http://www.ruscorpora.ru.

ОШ 1997 = ОЖЕГОВ С. И., ШВЕДОВА Н. Ю. (ред.) Толковый словарь русского языка. Москва, 1997.

ПОПОВА-СТЕРНИН 2007 = ПоПОВА З. Д., СТЕРНИН И. А. Когнитивная лингвистика. Москва, 2007.

УШАКОВ = УШАКОВ Д. Н. (ред.) Толковый словарь русского языка. Т. 1-4. Москва, $1935-1940$.

ФАСМЕР = ФАСМЕР Макс: Этимологический словарь русского языка. Т. 1-4. Москва, $1986-1987$.

ШАБАлИНА 2014 = ШАБАЛИНА А. Н. АНглийский coffee и русский кофе: языковая картина мира и воздействие культур. В кн.: НЕфедовА Л. А. (ред.) Слово, высказывание, текст в когнитивном, прагматическом и культурологическом аспектах. Челябинск, 2014. 527-531.

ШведОВА 2000 = ШвеДОВА Н. Ю. (ред.) Русский семантический словарь. Толковый словарь, систематизированный по классам слов и значений. Т. 2. Москва, 2000.

Шустов 1991 = Шустов А. Н. Кофейный дом. Русская речь 1991/2: 128-133.

DŁugosz-Kurczabowa 2008 = DŁugosz-KurCZABowa Krystyna: Wielki stownik etymologiczno-historyczny języka polskiego. Warszawa, 2008. 
HERBACZYŃSKI 1988 = HERBACZYŃSKI Wojciech: $W$ dawnych cukierniach $i$ kawiarniach warszawskich. Warszawa, 1988.

HOMOLA-SKĄPSKA 1996 = HOMOLA-SKĄPSKA Irena: Krakowskie cukiernie i kawiarnie w XIX wieku. Annales Universitatis Mariae Curie-Skłodowska. Sectio F, Historia 51. Lublin, 1996. 44-61.

KOPALIŃSKI 1999 = KOPALIŃSKI Władysław: Słownik wyrazów obcych i zwrotów obcojęzycznych. Warszawa, 1999.

NKJP = Narodowy korpus języka polskiego. http://www.nkjp.pl.

SEJP 1970 = BRÜCKNER Aleksander: Stownik etymologiczny języka polskiego. Warszawa, 1970.

SJPD = DoroszEWSKI Witold (red.): Stownik języka polskiego. T. 1-11. Warszawa, 19581969.

VANTAL 1998 = VANTAL Anne: Kawa-poradnik smakosza. Warszawa, 1998.

WSJP = Wielki stownik języka polskiego. http://www.wsjp.pl. 